\title{
STRATEGI KREATIF PROGRAMMER DALAM MENAIKAN EKSISTENSI PROGRAM SHIO ASIA DI TENGAH FENOMENA KOREAN WAVE
}

\author{
Gita Agnesia ${ }^{1}$, Luki Sahidan ${ }^{2}$ \\ ${ }^{1,2}$ Program Sarjana Ilmu Komunikasi \\ Sekolah Tinggi Ilmu Komunikasi Indonesia Maju \\ Jln. Harapan Nomor 50, Lenteng Agung - Jakarta Selatan 12610 \\ Telp: 02178894043 / 44, Email: ghita.agnezia@yahoo, 1sahidan@gmail.com
}

\begin{abstract}
Abstrak
Fenomena budaya populer Korea (Korean wave) kini membuat media penyiaran radio seakan berlomba-lomba memproduksi siaran yang berkaitan dengan budaya populer Korea, salah satunya RRI PRO 2 FM Jakarta dengan programnya Shio Asia. Untuk menaikan eksistensi RRI PRO 2 FM, khususnya program Shio Asia, menjadi suatu tantangan untuk mencari solusi, membuat trik atau strategi agar program tersebut dapat bertahan, dan diminati oleh kalangan muda. Metode yang digunakan dalam penelitian ini adalah metode penelitian kualitatif, dengan desain penelitian analisis fenomenologi. Penelitian ini dilakukan melalui wawancara, observasi, dan dokumentasi dengan informan yaitu programmer dan penyiar program Shio Asia. Berdasarkan hasil penelitian yang telah dilakukan, dapat disimpulkan bahwa programmer telah menerapkan strategi pemrograman yaitu; perencanaan program (planning), produksi/akuisi program (production), eksekusi program (execution), pengawasan dan evaluasi program (controlling), dan hal tersebut menghasilkan strategi kreatif seperti; mengubah jam siaran program Shio Asia menjadi lebih awal, mempertahankan pola siaran yang jelas, mengiklankan program Shio Asia di sela program lain, menetukan penyiar yang mempunyai passion tentang budaya populer Korea dan melaksanakan evaluasi secara rutin.
\end{abstract}

Kata Kunci : Strategi Kreatif, Programmer, Eksistensi.

\begin{abstract}
Korean popular culture phenomenon (Korean wave) is now making the radio broadcasting as if competing to produce broadcasts related to popular culture of Korea, one of them RRI PRO 2 FM Jakarta with the program of Shio Asia. To raise the existence of RRI PRO 2 FM, especially on the Shio Asia program, it is a challenge to find solutions, make tricks or strategies for surviving, better known and interested by the youth. This study used qualitative research methods. Because this research was done through interviews, observation, and documentation with relevant sources. The method used in this research is qualitative research method, with research design of phenomenology analysis. The research was conducted through interviews, observations, and documentation with the informants such as programmer and announcer of the program of Shio Asia. Based on the results of research that has been done, it can be concluded that the programmer has implemented a programming strategy that is; planning program, production/acquisition program, execution program, monitoring and evaluation program, and produce creative strategies such as; Shio Asia broadcast hours program early, Shio Asia program maintaining clear broadcast patterns, advertising Shio Asia programs in other programs, determine the announcer who has a passion about Korean popular culture, and evaluating program routinely.
\end{abstract}

Keywords: Creative Strategy, Programmer, Existence. 


\section{Pendahuluan}

Dalam kehidupan sehari-hari, manusia membutuhkan sebuah media untuk saling bertukar informasi. Cara ini dikenal dengan istilah komunikasi. Melalui komunikasi, seseorang dapat menyampaikan sebuah berita, saling bertukar informasi, menyampaikan sebuah gagasan atau ide, maupun bersosialisasi dengan orang lain.

Sebuah informasi dapat secara cepat tersampaikan kepada masyarakat luas melalui sebuah media yang disebut sebagai media massa. Media massa adalah sebuah channel atau tempat yang digunakan sebagai sarana dalam proses komunikasi massa. Media massa menunjukan seluruh sistem di mana pesanpesan diproduksikan, dipilih, disiarkan, diterima dan ditanggapi masyarakat. Pesan komunikasi yang disampaikan melalui media massa adalah terbuka untuk semua orang. Media massa tersebut seperti televisi, radio, dan media cetak. Media massa merupakan saran terorganisasikan dan terlembagakan; karenanya komunikator media massa seperti umpamanya penyiar dan wartawan (Effendy, 1983:12) ${ }^{1}$.

Sebagai salah satu media massa elektronika, radio mempunyai sifat-sifat khusus yang dapat dijadikan sebagai kekuatan yang dimiliknya dalam menyampaikan pesan atau informasi kepada masyarakat. Lambang komunikasi radio bersifat auditif alias hanya menerpa indera telinga (Moeryanto, 1996:12) ${ }^{2}$.

Dalam kegiatan siaran, suatu media massa khususnya radio, tidak terlepas dari program. Yang mana program merupakan produk siaran dari media itu sendiri. Kata Program berasal dari bahasa Inggris "Programme" yang berarti acara atau rencana. Program adalah segala hal yang ditayangkan media penyiaran untuk memenuhi kebutuhan audiennya (Triartanto, 2010) ${ }^{3}$.

PRO 2 RRI Jakarta merupakan salah satu dari lima Programa (stasiun radio) yang dinaungi oleh LPP RRI (Lembaga Penyiaran Publik Radio Republik Indonesia) yang segmentasi siarannya dikhususkan untuk siaran hiburan dengan target audiennya adalah pendengar remaja dan pemuda di Jabodetabek. Salah satu program hiburan yang cukup dikatakan "berbeda" dari program lainnya dan "mengikuti perkembangan zaman" adalah program Shio Asia.
Shio Asia adalah program siaran hiburan yang menyajikan konsep siaran mengenai informasi berbau budaya populer Korea. Budaya populer Korea atau dikenal dengan istilah kerennya K-Pop, merupakan segala hal yang berkaitan dengan adat kebiasaan yang ada di negeri ginseng Korea. K-pop melanda hampir diseluruh negara di Asia termasuk Indonesia dan bahkan sampai ke Eropa dan beberapa negara Timur Tengah.

Fenomena budaya populer Korea (Korean wave) merupakan fenomena yang berkaitan dengan maraknya musik dan lagu-lagu pop Korea (K-pop: Korean pop) yang tengah digandrungi oleh kaum muda di berbagai negara. K-pop sendiri adalah salash satu aliran musik yang memadukan gaya bermusik populer ala Amerika seperti rap, rock, hip-hop, dan techno. Namun pada saat ini, Korean wave diikuti dengan banyaknya perhatian akan produk Korea Selatan, seperti masakan, barang elektronik, musik, film dan drama. Fenomena ini turut mempromosikan Bahasa Korea dan budaya Korea ke berbagai negara (Kristie Lee, hal:3) ${ }^{4}$

Program siaran budaya populer Korea sudah banyak ditayangkan di media televisi. Beberapa contoh diantaranya, Stasiun TV Indosiar, RCTI dan ANTV yang gemar menayangkan drama-drama dan musik pop Korea. Begitupun dengan media cetak dan radio. Dalam dunia penyiaran radio, siaran tentang budaya populer Korea tersebut memang masih terbilang produk baru. Karena baru beberapa stasiun radio yang menyajikan program tersebut.

Sebagai sebuah program yang menyiarkan informasi budaya populer Korea, Shio Asia tidak lepas dari persaingan merebut hati audiens, khususnya bagi para pecinta budaya populer Korea. Hal ini tentunya menjadi tantangan bagi Tim Kreatif sebuah stasiun radio, terutama seorang Programmer.

Bagi sebagian kalangan muda di Jakarta dan sekitarnya yang gemar mendengarkan siaran hiburan dari radio swasta, mungkin masih asing dengan program radio Shio Asia di RRI PRO 2 Fm Jakarta.

Hal tersebut dapat terlihat dari data Cumulative Audience lembaga riset media, yaitu PT The Nielsen Company Indonesia berikut ini: 
Tabel 1. Rating \& Profil Stasiun Radio RRI PRO 2 FM Jakarta.

Station Rating PRO 2 Jakarta, People 10+

\begin{tabular}{|l|c|c|}
\hline Station & $\begin{array}{c}\text { Cumulative } \\
\text { Audience }\end{array}$ & T.S.L \\
\hline PRO 2 & 125.000 & $0: 38$ \\
\hline
\end{tabular}

Station Profile PRO 2 Jakarta, People 10+

\begin{tabular}{|l|l|c|}
\hline Station & Target & Cume \\
\hline \multirow{5}{*}{ PRO 2 } & Male & 60.000 \\
\cline { 2 - 3 } & Female & 65.000 \\
\cline { 2 - 3 } & $10-14$ years & 0 \\
\cline { 2 - 3 } & 15-19 years & 25.000 \\
\cline { 2 - 3 } & 20-29 years & 21.000 \\
\cline { 2 - 3 } & 30-39 years & 26.000 \\
\cline { 2 - 3 } & 40-49 years & 35.000 \\
\cline { 2 - 3 } & 50+ years & 16.000 \\
\cline { 2 - 3 } & Upper & 33.000 \\
\cline { 2 - 3 } & Middle & 58.000 \\
\cline { 2 - 3 } & Lower & 34.000 \\
\hline
\end{tabular}

Sumber: Data Riset Media PT The Nielsen Company Indonesia.

Hasil dari data riset tersebut membuktikan bahwa audien yang mendengarkan siaran di RRI PRO 2 FM Jakarta berjumlah 125.000 orang. Sehingga dapat disimpulkan, bahwa RRI PRO 2 Fm Jakarta mempunyai cukup banyak peminat namun belum begitu eksis sebagai radio bagi kaum remaja.

Permasalahan yang berkaitan dengan dunia penyiaran radio sangatlah luas. Oleh karena itu penelitian ini dilakukan bertujuan untuk mengetahui strategi kreatif yang dilakukan programmer untuk menaikan eksistensi program Shio Asia di PRO 2 RRI Jakarta ditengah fenomena Korean wave.

\section{Metode}

Penelitian ini merupakan penelitian analisis deskriptif dan dengan menggunakan pendekatan kualitatif. Dengan menguraikan atau mendeskripsikan hal apa saja yang menjadi tindakan, langkah atau strategi yang dilakukan oleh programmer guna menaikkan eksistensi program Shio Asia di tengah fenomena Korean wave.

Desain dalam penelitian ini menggunakan desain penelitian analisis fenomenologi. Di mana dalam penelitian fenomenologi penulis mencoba memahami arti peristiwa dan kaitankaitannya terhadap orang-orang biasa dalam situasi-situasi tertentu, menjelaskan atau mengungkap makna konsep atau fenomena pengalaman yang didasari oleh kesadaran yang terjadi pada beberapa individu.

Seperti teori yang diungkapkan Rini Sudarmanti (2005), fenomenologi bertujuan untuk menginterpretasikan tindakan sosial kita dan orang lain sebagai sebuah yang bermakna (dimaknai).

Instrumen yang digunakan dalam melakukan penelitian ini adalah dengan observasi dan wawancara, yaitu dengan mengamati proses siaran berlangsung, kemudian mewawancarai sumber informan dengan mengajukan pertanyaan-pertanyaan yang sebelumnya telah disusun oleh penulis yang berupa pedoman wawancara, yakni ${ }^{5}$ :

Pedoman Wawancara Mengenai Program Shio Asia.

Pedoman Wawancara Mengenai Strategi Pemrograman.

Teknik analisis data yang dilakukan yaitu melalui proses pengumpulan data (data collection), reduksi data (data reduction), penyajian data (data display), penarikan kesimpulan (conclusion: verifying) ${ }^{6}$.

\section{Hasil dan Pembahasan}

Fokus utama penelitian ini adalah mencari tahu strategi kreatif yang dilakukan programmer untuk menaikan eksistensi program Shio Asia di PRO 2 RRI Jakarta ditengah fenomena Korean wave. Diketahui bahwa strategi yang diterapkan oleh programmer pada program Shio Asia untuk menaikkan eksistensi program tersebut adalah dengan melewati beberapa tugas programmer prinsip programmer, dan juga empat tahap strategi pemrograman ${ }^{7}$.

Beberapa Tugas yang Telah Dilakukan Programmer Dalam Menaikkan Eksistensi Program Shio Asia, yaitu meliputi:

Melakukan penggabungan isi dan produksi program yang diminati oleh target audien. Di RRI PRO 2 FM Jakarta, beberapa progam siaran ber-format hiburan mempunyai peminat tersendiri dengan hasil persentase audien lebih banyak daripada program ber-format informasi, pendidikan, budaya, dan lain-lain. Hal tersebut dapat dilihat dari daftar persentase spesifikasi rencana siaran berdasarkan klasifikasi format program di RRI PRO 2 FM Jakarta di bawah ini: 
Tabel 2. Persentase Spesifikasi Rencana Siaran

\begin{tabular}{|c|c|c|c|c|}
\hline \multirow{2}{*}{$\begin{array}{l}\text { Klasifikasi } \\
\text { Siaran }\end{array}$} & \multicolumn{4}{|c|}{ Day Part } \\
\hline & Pagi & Siang & Sore & Malam \\
\hline Informasi & 3,060 & 3,875 & 2,768 & 2,213 \\
\hline Pendidikan & 437 & 434 & 276 & 318 \\
\hline Budaya & 276 & 434 & 276 & 318 \\
\hline Hiburan & 4,163 & 4,774 & 3,035 & 3,478 \\
\hline Penunjang & 1,679 & 1,643 & 1,085 & 1,116 \\
\hline \multicolumn{5}{|c|}{ Akumulasi } \\
\hline Jumlah & \multicolumn{3}{|c|}{ Persentase } & Pedoman \\
\hline 11,916 & \multicolumn{3}{|c|}{33,57} & 30 \\
\hline 1,453 & \multicolumn{3}{|c|}{4,12} & 5 \\
\hline 1,302 & \multicolumn{3}{|c|}{3,67} & 5 \\
\hline 15.450 & \multicolumn{3}{|c|}{43,53} & 45 \\
\hline 5,363 & \multicolumn{3}{|c|}{16,11} & 15 \\
\hline
\end{tabular}

\begin{tabular}{|l|l|l|l|}
\hline Jumlah & $35.495,0$ & 100 & 100
\end{tabular}

Sumber: Arsip RRI PRO 2 FM Jakarta.

Berdasarkan persentase tersebut menunjukkan bahwa di RRI PRO 2 FM Jakarta seluruh program dengan format hiburan sangat diminati oleh masyarakat. Maka dari itu, dalam tugas ini programmer bertanggung jawab dan memperhatikan kematangan program Shio Asia. Dari mulai menentukan arah konten hingga pengemasan program Shio Asia yang sederhana namun tetap menarik.

Mampu melakukan penjadwalan program agar sesuai dengan waktu audien mendengarkan program. Dalam melakukan tugas penjadwalan program, di RRI PRO $2 \mathrm{Fm}$ Jakarta semua crew divisi program (produser, programmer, penyiar) tentunya telah melakukan penjadwalan waktu siaran terlebih dulu.

Menyusun produksi iklan, pengumumanpengumuman, dan iklan layanan masyarakat. Programmer lebih berkutat pada pemrograman tidak terlibat langsung dalam mengatur produksi iklan.

Menentukan penyiar. Dalam tugas menentukan penyiar RRI PRO 2 Fm Jakarta yang merupakan radio bertarget audien kalangan muda, programmer memilih penyiar yang friendly (ramah), memiliki passion atau ketertarikan akan konsep program yang dibawakannya, dan tentunya berusia muda.
Bertanggung jawab atas siaran yang mengudara di stasiun radio tersebut. Dalam tugas ini, Fajar dan Ferli yang merupakan penyiar program Shio Asia bertanggung jawab atas siaran yang berlangsung. Seperti pada suatu kejadian yang dialami Fajar maupun Ferli saat program Shio Asia yang tengah mengudara mengalami gangguan teknis. Sebagai programmer ataupun penyiar Fajar dan Ferli berusaha profesional dengan memperbaiki gangguan pada teknis dalam studio dan kemudian memberi informasi pada audien bahwa program Shio Asia sedang mengalami gangguan teknis.

Memahami penempatan program yang tepat sesuai waktu, durasi, dan juga program demi program, supaya pendengar tetap konsisten dalam mendengar program radionya (stay tune). Dalam hal ini divisi program di RRI PRO 2 Fm Jakarta, bekerjasama dalam menempatkan jadwal program, yaitu yang sesuai dengan waktu mendengar siaran radio.

\section{Prinsip Programmer Dalam Mengkoordinasi Program Siaran:}

\section{Regularity (Pola program).}

Programmer harus membuat pola program teratur untuk membangun pendengar reguler. Berdasarkan dari data yang didapat, menjelaskan dalam hal ini programmer berusaha untuk tetap konsisten pada programnya dengan pola, format siaran dan segmen-segmen program yang telah ditetapkan sebelumnya. RRI PRO 2 FM Jakarta memiliki suatu pola acara siaran yang didalamnya semua program telah tersusun secara sistematis yang dinamakan "day part". Day part tersebut terbagi ke dalam empat waktu, yakni Jakarta Pagi Ini pukul 05.00 s.d. 10.00 WIB, Panorama Jakarta pukul 10.00 s.d. 16.00 WIB, Jakarta Sore Ini pukul 16.00 s.d. 20.00 WIB, dan Nuansa Jakarta Metropolis pukul 20.00 s.d. 24.00 WIB. Demikian program Shio Asia termasuk dalam day part Nuansa Jakarta Metropolis dengan jadwal program pukul 20.00 s.d. $24.00 \mathrm{WIB}$.

\section{Repetition (Pengulangan).}

Pengulangan diperlukan untuk "pembelajaran oral". Dalam hal ini di RRI PRO 2 FM Jakarta, repetition atau pengulangan merupakan suatu evaluasi program yang dilakukan dengan mendengarkan ulang siaran yang telah berlangsung dan telah direkam dalam ruang "master control room". Bukan hanya program 
Shio Asia, namun juga berlaku untuk semua program. Hal tersebut dilakukan untuk mencari letak kekurangan siaran yang telah on air. Sehingga dilain waktu kesalahan-kesalahan dalam siaran tidak terulang kembali.

\section{Suitability}

(Kesesuaian "rasa" dan "kebutuhan" pendengar).

Program radio harus sesuai dengan "rasa" dan "kebutuhan" pendengar. Dalam aspek suitability ini, programmer telah berusaha menyesuaikan programnya sesuai selera pasar. Contohnya pada program Shio Asia yang mengikuti perkembangan zaman dan yang sedang diminati oleh kalangan muda, yakni dengan memiliki konten yang bertema budaya populer Korea dan lebih banyak menyuguhkan segmen-segmen request lagu sekaligus kirim salam oleh audien. Hal tersebut rupanya berhasil membuat audien menyukai segmen request lagu dalam program Shio Asia.

\section{Exploitation of Censorship}

\section{(Sensor internal akan visi dan misi radio).}

Ada sensor internal untuk materi siaran agar tetap sesuai dengan visi dan misi radio, kebutuhan pendengar, dan kode etik penyiaran. Dalam prinsip ini, programmer program Shio Asia tentunya melakukan sensor internal dalam program siarannya. Seperti pada programprogram yang disiarkan di RRI PRO 2 FM Jakarta jika dilihat dari konsep materinya tetap mengikuti perkembangan jaman, yaitu memenuhi kebutuhan informasi yang diinginkan kalangan muda, namun tetap tidak kehilangan jati dirinya sebagai lembaga penyiaran publik "milik pemerintah" yang melayani masyarakat melalui informasi siarannya.

\section{Voice}

\section{(Pemilihan penyiar yang tepat).}

Penyiar merupakan unsur penting dalam siaran. Penyiar merupakan ujung tombak dalam program siaran yang memainkan peran penting dalam penyiaran radio. Dalam aspek voice, Fajar seorang programmer yang juga terlibat sebagai penyiar utama program Shio Asia, sebelumnya memang tertarik pada hal yang berkaitan budaya populer Korea. Sehingga Fajar dapat menguasai konten siaran yang dibawakannya dengan gaya siaran yang atraktif dan tidak terkesan flat (datar) sesuai dengan kriteria aspek voice tersebut.

\section{Strategi Khusus Programmer Dalam Menaikan Eksistensi Program Shio Asia Ditengah Fenomena Korean Wave:}

Programmer program Shio Asia yang memiliki strategi pemrograman dalam menaikan eksistensi programnya ditengah fenomena Korean wave yang meliputi; 1) perencanaan program, 2) akuisi program, 3) eksekusi program, dan 4) evaluasi program program $^{8}$.

\section{Perencanaan Program (Planning).}

Program Shio Asia merupakan program siaran khusus dan memiliki konsep yang berbeda dengan program siaran lainnya yang ada di RRI PRO 2 Fm Jakarta. Sehingga dalam perencanaan produksinya harus benar-benar memperhatikan format, materi, sasaran audien, dan lain sebagainya. Dalam memproduksi programnya, programmer telah melakukan

sebuah strategi awal yaitu seperti mempertimbangkan penempatan waktu siaran, berupaya mengidentifikasi audien yang spesifik, mengetahui kapan biasanya khalayak mendengar siaran radio, dan seperti apa konsep atau materi yang tepat untuk program bertema budaya populer Korea tersebut. Dari perencanaan program tersebut, programmer menghasilkan strategi yaitu menempatkan waktu siar program Shio Asia lebih awal yaitu pukul 20.00 malam, karena sebelumnya disiarkan pukul 21.00 malam, hal itu dilakukan agar dapat menarik lebih banyak audien dengan waktu siar yang "tidak terlalu malam".

\section{Produksi atau Akuisisi Program (Production).}

Program biasanya bisa diperoleh dengan cara membeli atau memproduksinya sendiri. Suatu program yang dibuat sendiri oleh media penyiaran disebut dengan istilah "in house production" atau produksi sendiri. Jika program dibuat pihak lain, berarti stasiun penyiaran membeli program tersebut. Dalam strategi produksi/akuisisi program ini, RRI PRO 2 Fm Jakarta memproduksi programnya sendiri (in house production). Sebagaimana program radio pada umumnya, program Shio Asia memiliki pola program yang teratur seperti adanya opening dan closing jinggle sebagai penanda mulai dan berakhirnya program, kemudian ada bridging yang berfungsi untuk mencegah audien agar tidak berpindah channel atau frekwensi, dan terakhir 
terselip promo program (iklan) untuk mengingatkan para audien akan jadwal program lain yang seolah-olah "sayang" untuk dilewatkan.

\section{Eksekusi Program (Execution).}

Eksekusi program merupakan, suatu kegiatan menayangkan atau menyiarkan program sesuai dengan rencana yang telah ditetapkan. Seperti halnya di RRI PRO 2 Fm Jakarta dalam program Shio Asia, programmer berusaha melakukan teknik penempatan program tersebut sebaik-baiknya guna mendapatkan hasil yang optimal. Berdasarkan hasil penelitian dilapangan diketahui bahwa, saat eksekusi program atau ingin memulai siaran pada program Shio Asia, crew yang bertugas harus sudah mempersiapkan diri terlebih dulu sesuai jadwalnya. Karena biasanya di RRI PRO 2 Fm, pada program Shio Asia terdapat pergantian jadwal penyiar. Pergantian penyiar tersebut dilakukan dalam periode hitungan bulan ataupun tahun.

Namun yang berbeda disini adalah, sebuah strategi dalam penyajian segmen-segmen yang akan disiarkan, yang tergantung oleh penyiar yang on air saat itu. Seperti contoh, jika pada suatu periode penyiarnya adalah Fajar, maka segmen-segmen seperti Hallyu Battle, New Entry Shio Asia, dan Fanbase Show tetap dilaksanakan saat siaran. Lain halnya pada saat periode Ferli, segmen-segmen yang telah ditetapkan tidak semuanya disajikan, hanya New Entry Shio Asia yaitu membacakan request-an lagu maupun salam dari para audien melalui media sosial whatsapp, twitter, instagram, dan sms. Penyajian segmen yang berbeda yang tergantung oleh penyiar, diharapkan dapat menciptakan suasana siaran yang berbeda bagi audien. Kemudian tahapan dalam strategi eksekusi program selanjutnya adalah mulai melakukan siaran secara on air. Dalam program Shio Asia tidak ada tema khusus sebagai pembahasan di setiap siarannya.

\section{Pengawasan dan Evaluasi Program (Controlling).}

Proses pengawasan dan evaluasi menentukan seberapa jauh suatu rencana dan tujuan yang sudah dapat dicapai oleh stasiun penyiaran tersebut.

Demikian strategi pengawasan dan evaluasi program yang dilakukan di RRI PRO 2 Fm Jakarta. Demi keberhasilan program siaran di RRI PRO 2 Fm Jakarta, Fajar selaku penyiar sekaligus programmer Shio Asia beserta semua crew dan Kepala Bidang Perencana Evaluasi Programa II yaitu H. Karsila, rutin melakukan rapat evaluasi program dengan periode satu kali dalam se-tahun. Dalam rapat evaluasi tersebut, membahas segala kelebihan dan kekurangan yang harus dipertahankan maupun diperbaiki dalam hal kinerja crew dan juga program acara. Selain itu, hasil dari rapat evaluasi yang pernah dilakukan saat beberapa tahun silam, membawa dampak perubahan tersendiri bagi program Shio Asia dalam hal konten dan waktu siaran.

Upaya perubahan tersebut nyatanya membuat program Shio Asia semakin menarik respon audien. Dengan konten yang mengikuti keinginan pasar yaitu lebih banyak menyajikan lagu-lagu populer Korea dibanding Jepang dan Mandarin. Kemudian dari segi waktu yang efektif, dimana waktu siaran yang lebih awal

yaitu pukul 20.00 malam biasanya kalangan muda yang mayoritas berstatus pelajar pada jam tersebut masih dalam aktifitas santai ataupun belajar sambil mendengarkan radio, bahkan me-request lagu kesukaannya.

\section{Respon Audien Terhadap Eksistensi Program Shio Asia.}

Mengetahui secara persis seperti apa respon audien terhadap suatu program, merupakan hal yang penting yang mungkin dapat dijadikan sebagai bahan evaluasi untuk keberhasilan program tersebut.

Berikut adalah uraian respon dari beberapa audien mengenai eksistensi program Shio Asia yang diklasifikasikan ke dalam beberapa aspek:

\section{Bentuk Media}

Seperti yang diketahui, radio merupakan media massa yang menggunakan lambang komunikasi berupa bunyi/suara. Terkait dengan itu, maka radio siaran perlu dimuati pesan-pesan, informasi, musik, serta bunyi lainnya yang tersusun menjadi suatu program acara. Proses pengawasan dan evaluasi menentukan seberapa jauh suatu rencana dan tujuan yang sudah dapat dicapai oleh stasiun penyiaran tersebut.

Dalam memanfaatkan fungsi radio, para kreator stasiun penyiaran RRI PRO 2 Fm Jakarta berusaha memproduksi program acara yang menarik dan dapat diterima masyarakat. Salah satu program acara tersebut adalah Shio Asia. Program Shio Asia yang konsepnya 
mengikuti perkembangan zaman, serta disiarkan dalam media radio yang "fleksibel", nyatanya sangat pas dan efektif untuk menarik minat masyarakat mendengarkan radio.

Seperti pernyataan salah satu audien yang mengikuti program Shio Asia, saat ditanya alasan mengikuti program Shio Asia (selain karena menyukai K-pop):

"Program tersebut banyak info dan berita terup to date. Karena saya sibuk kerja, jadi kadang nggak mesti cek di medsos" (Fitri).

Dari pernyataan tersebut Fitri sebagai audien mengungkapkan bahwa Ia merasa tepat menggunakan media radio sebagai sarana sumber informasi yang praktis dan up to date ditengah kecanggihan media online. Selain itu, dengan penyajian program Shio Asia dalam media radio yang "praktis", membuat program tersebut masih tetap diminati.

\section{Konsep Program}

Program acara yang disajikan adalah faktor yang membuat audien tertarik untuk mengikuti siaran yang dipancarkan sebuah stasiun penyiaran. Materi program yang dipilih haruslah yang bagus dan diharapkan dapat disukai oleh audien yang dituju.

Program Shio Asia merupakan salah satu program siaran yang paling mengikuti zaman dan juga unik diantara program lainnya. Disaat program lain menyiarkan konsep tentang talk show, olahraga, musik pop Indonesia, dan lain sebagainya, justru Shio Asia hadir sebagai program yang seolah-olah menjawab kebutuhan informasi akan budaya populer Korea yang tengah digemari kalangan muda saat ini. Seperti respon positif pada program Shio Asia yang diungkapan salah satu audien:

"Program Shio Asia udah bagus, jangan sampai hilang aja, soalnya susah banget cari program radio yang bisa muter lagu $K$-pop" (Fitri).

Siaran radio yang memiliki konsep tentang budaya populer Korea masih terbilang baru dan unik. Dan saat ini beberapa stasiun radio swasta di Indonesia berlomba-lomba ikut menyajikan program siaran dengan konsep tersebut. Dengan kepandaian dan kekratifitasan stasiun penyiaran dalam memproduksi programnya yang mengikuti trend, dapat menjadi keuntungan tersendiri bagi stasiun penyiaran yang bersangkutan.

\section{Format Program}

Format program merupakan suatu batasan mengenai ciri tentang suatu program. Dengan adanya format program, pendengar dapat menikmati siaran radio sesuai dengan minat dengarnya. Saat ini, bukan hanya format musik pop Indonesia dan Mancanegara yang mempunyai banyak peminat, namun format musik pop Korea juga tidak kalah menariknya dimata pecinta budaya populer Korea. Seperti Shio Asia yang merupakan salah satu program dengan format musik pop Korea.

Shio Asia yang memiliki beberapa segmen menarik yang menjadi alasan audien mengikuti program tersebut, yakni; Hallyu Battle, New Entry Shio Asia, dan Fanbase Show. Para audien yang mengikuti program Shio Asia, rata-rata diantara mereka menyukai segmen saat membacakan request dan salam yaitu New Entry Shio Asia, dan segmen saat

menghadirkan narasumber untuk berbagi cerita dalam Fanbase Show. Selain materi siaran dan segmen, format program yang unik juga menjadi ciri khas program Shio Asia yang membuat para audien tertarik mendengarnya.

\section{Penyiar}

Penyiar merupakan seorang yang bertugas menyampaikan materi siaran melalui tuturan kata-kata kepada audien. Dalam program Shio Asia, selain konten programnya yang "dicari" oleh para audien, sosok penyiar juga menjadi alasan mereka mengikuti program tersebut. Para audien mengungkapkan ketertarikannya akan "gaya bicara" atau air personality Fajar dan Ferli yang terkesan "asik dan seru" saat membawakan program Shio Asia.

\section{Kesimpulan}

Dalam menaikkan eksistensi program Shio Asia di tengah fenomena Korean wave, programmer telah menerapkan beberapa strategi kreatifnya, yakni: mengubah jam siaran program Shio Asia menjadi lebih awal, program Shio Asia mempertahankan pola siaran yang jelas, mengiklankan program Shio Asia di sela program lain, menentukan penyiar yang dapat membangkitkan suasana siaran dan melaksanakan evaluasi secara rutin. Selain strategi kreatif yang mutlak dilakukan programmer untuk menaikkan eksistensi program Shio Asia, beberapa tugas dan prinsip 
programmer yang telah dipaparkan sebelumnya, juga yang memiliki pengaruh penting bagi keberlangsungan program Shio Asia. Sehingga dapat disimpulkan bahwa, di tengah fenomena Korean wave yang sedang mewabah dikalangan remaja, program Shio Asia selalu berusaha menaikan eksistensinya dengan menyajikan pengemasan programnya yang menarik seperti dari aspek materi program, konsep program, dan penyiar.

\section{Saran}

Berdasarkan penelitian yang dilakukan, ada beberapa saran yang dapat peneliti sampaikan adalah sebagai berikut:

Untuk pengelola program Shio Asia, alangkah baiknya jika segmen Hallyu Battle, dan Fanbase Show tetap ada saat jadwal penyiar Ferli. Meskipun perbedaan segmen tersebut berguna agar audien tidak bosan, namun kekonsistenan segmen yang tetap terjaga baik saat jadwal penyiar Fajar maupun Ferli juga sangat penting.

Melakukan promosi program dengan lebih aktif terutama di media sosial.

Perlunya pengemasan yang lebih menarik pada program Shio Asia dengan membuat tema yaitu seperti, pembahasan khusus tentang girlband atau boyband, penyanyi solois Korea, drama Korea, variety atau reality show Korea, dan sebagainya. pada setiap siaran.

Maksimalkan penerapan strategi kreatif yang selama ini diterapkan agar program Shio Asia semakin baik ke depannya.

\section{Daftar Pustaka}

1. Effendy, Onong Uchjana. Radio Siaran Teori \& Praktek. Bandung: Penerbit Alumni. 1983

2. Moeryanto. Media Komunikasi Radio. Jakarta: Pustaka Sinar Harapan. 1996

3. Triartanto, A. Ius Yudo. Broadcasting Radio Panduan Teori dan Praktik. Yogyakarta: Pustaka Book Publisher. 2010

4. Lee, Kristie. K-pop Legends. Jakarta: PT. Grasindo.

5. Sugiyono. Metode Penelitian Kuantitatif, Kualitatif, dan R\&D. Bandung: Alfabeta. 2016

6. W.Creswell, John. Research Design Pendekatan Kualitatif, Kuantitatif, dan Mixed. Yogyakarta: Pustaka Pelajar. 2013

7. M.Romli, Asep Syamsul. Dasar-Dasar Siaran Radio: Basic Announcing. Bandung: Penerbit Nuansa. 2009.

8. Morissan. Manajemen Media Penyiaran: Strategi Mengelola Radio \& Televisi. Jakarta: Prenada Media Group. 2013 